\title{
Characterizing Farmers' Market Shoppers: A Literature Review
}

\section{Authors: Carmen Byker, Justin Shanks, Sarah Misyak, \& Elena Serrano}

This is an Accepted Manuscript of an article published in Journal of Hunger and Environmental Nutrition on January 2012, available online: http://www.tandfonline.com/10.1080/19320248.2012.650074.

Byker, C., Shanks, J., Misyak, S., \& Serrano, E. "Characterizing Farmers Market Shoppers: A Literature Review. Journal of Hunger and Environmental Nutrition." 7, no. 1 (January 2012): 38-52. 


\title{
Characterizing Farmers' Market Shoppers: A Literature Review
}

\author{
Carmen Byker ${ }^{1}$, Justin Shanks², Sarah Misyak ${ }^{3}$, \& Elena Serrano ${ }^{3}$ \\ ${ }^{1}$ Montana State University, Department of Health and Human Development, \\ Bozeman, Montana, USA \\ ${ }^{2}$ Virginia Tech, Department of Science Technology in Society, \\ Blacksburg, Virginia, USA \\ ${ }^{3}$ Virginia Tech, Department of Human Nutrition, Foods and Exercise, \\ Blacksburg, Virginia, USA
}

\begin{abstract}
The number of farmers' markets in the United States continues to grow, suggesting an increasing interest in community food systems. Yet, little conclusive research has been conducted to characterize farmers' market customers. The purpose of this literature review is to more definitively examine the current farmers' market consumer base established in published research studies. We explore demographic factors as well as motivations and barriers for farmers' markets shoppers. Based on current research, it is clear that an assortment of complex and interrelated factors influence an individual's choice to shop at farmers' markets and that a more consistent data gathering method is needed.
\end{abstract}

A food system encompasses all people and processes related to food, including agricultural production, processing, packaging, distribution, marketing, consumption, and disposal. ${ }^{1}$ In an effort to rethink the modern configuration (ie, conventional agriculture), a growing number of individuals are engaging in more localized and community-based food systems (or what is often referred to as a foodshed) in lieu of a larger, more industrialized 
and anonymous conventional structure. ${ }^{2}$ Whereas the modern conventional food system broadens food cycle inputs and outputs to a global scale, a community-based food system is conceptualized as one where all of the components are localized to a particular place. ${ }^{3}$ Community food systems ultimately aim to attain food security (for individuals as well as entire communities), relational proximity, self-reliance, and sustainability. ${ }^{1}$

The explosive growth of farmers' markets in recent years demonstrates increasing interest in community food systems. In 1994, the US Department of Agriculture's (USDA) Agricultural Marketing Service tallied 1755 farmers' markets nationally. ${ }^{4}$ By the end of 2004 that number grew to 3706; and in 2010, 6132 farmers' markets were reported. ${ }^{4}$ With such rapid growth, farmers' markets have become more pervasive features in many food environments and an increasingly familiar food system concept. Yet little conclusive research has been conducted to characterize farmers' market customers, although the popular press has claimed that farmers' markets attract more patrons of higher education and income levels and fewer patrons from disparate audiences. ${ }^{5}$

As a result, it is important to understand how farmers' markets play a role in the local food environment and, if not reaching broader underserved audiences, strategize ways to improve access and utilization. To further diversify the farmers' market base, it is critical to determine whether there are socioecological factors that might encourage demographically diverse consumers to shop at the farmers' market. From a socioecological perspective, individual choices are mediated by a variety of contextual factors. ${ }^{6}$ Individual, relational, organizational, community, social, and cultural elements are all in play when consumers make choices within their food environment and food system. The decision to shop (or not to shop) at the farmers' market is just one of the choices consumers make as a result of their own socioecological matrix. The purpose of this literature review is to examine the current farmers' market consumer base established in published research studies and then to further outline the research needs surrounding farmers' market use.

\section{METHODOLOGY}

Social and behavioral science peer-reviewed articles were identified using ISI Web of Knowledge, PubMed, Informaworld, ScienceDirect, and Google Scholar databases. To identify pertinent articles about consumers, the term farmers' market was combined with the following words: demographics, income, education, age, gender, race, ethnicity, employment, and consumer.

For each pairing of search terms, titles and abstracts were used to identify articles related to each categorical topic. Articles were included if 
the following 3 criteria were met: published between January 2005 and December 2010; found using identified search terms through the aforementioned journal databases; and peer reviewed. Relevant articles were retrieved and annotated within each category. A snowball technique was used with reference sections of retrieved articles to identify other relevant studies. In all, 22 relevant articles regarding consumer research and farmers' markets were included in the literature review. Research findings were reviewed and validated by 2 other researchers. The studies included in this review used a range of methodologies to obtain information about farmers' market shoppers, including various survey formats and interviewing.

\section{RESULTS}

The following review attempts to highlight consistencies and inconsistencies reported in farmers' market consumer data and characteristics. Table 1 summarizes the results.

\section{Gender}

Research from reviewed literature suggests that farmers' market patrons are more likely to be female. Six studies conducted in various regions of the United States used written surveys to collect demographic characteristics on-site (ie, at farmers' markets). At least $64 \%$ and up to $77 \%$ of written

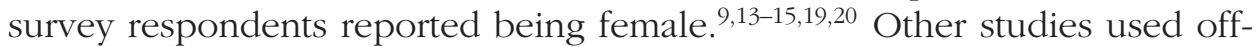
site survey methods to gather state and nationwide representative samples of farmers' market shoppers. Consistent with other studies, Zepeda conducted a nationwide telephone and mail survey to identify differences in market shoppers and nonshoppers and reported that market shoppers were more likely to be female. ${ }^{22}$ A Michigan telephone survey also found that females were more motivated to attend farmers' markets. ${ }^{12}$

To define characteristics of direct-market shoppers, Onianwa and colleagues collected telephone survey data in Alabama. ${ }^{16}$ In contrast to other studies, they found that males were more likely to purchase from directmarket outlets; however, direct-market outlets were broad and did not separate shoppers of roadside stands, tailgate vehicles, and U-picks from farmers' markets.

It is possible to explain these findings about gender through a comparison with the findings in other studies about consumer attitudes regarding food purchases. Bellows et al explored the extent to which gender plays a role in shaping consumer attitudes regarding organic, local, US-grown, and genetically modified foods. ${ }^{10}$ According to their study, a majority of females were responsible for cooking and food shopping and had strong attitudes 


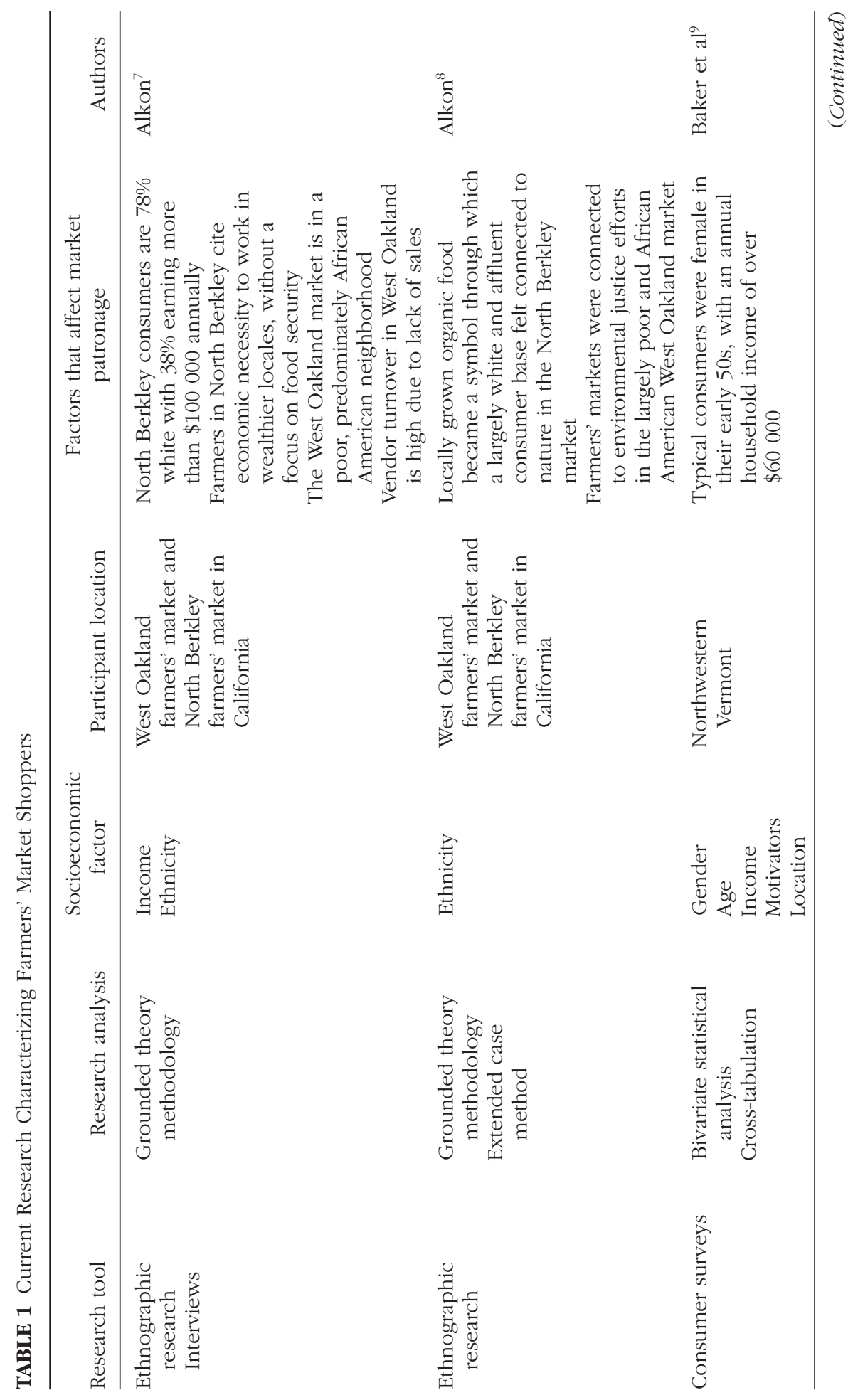




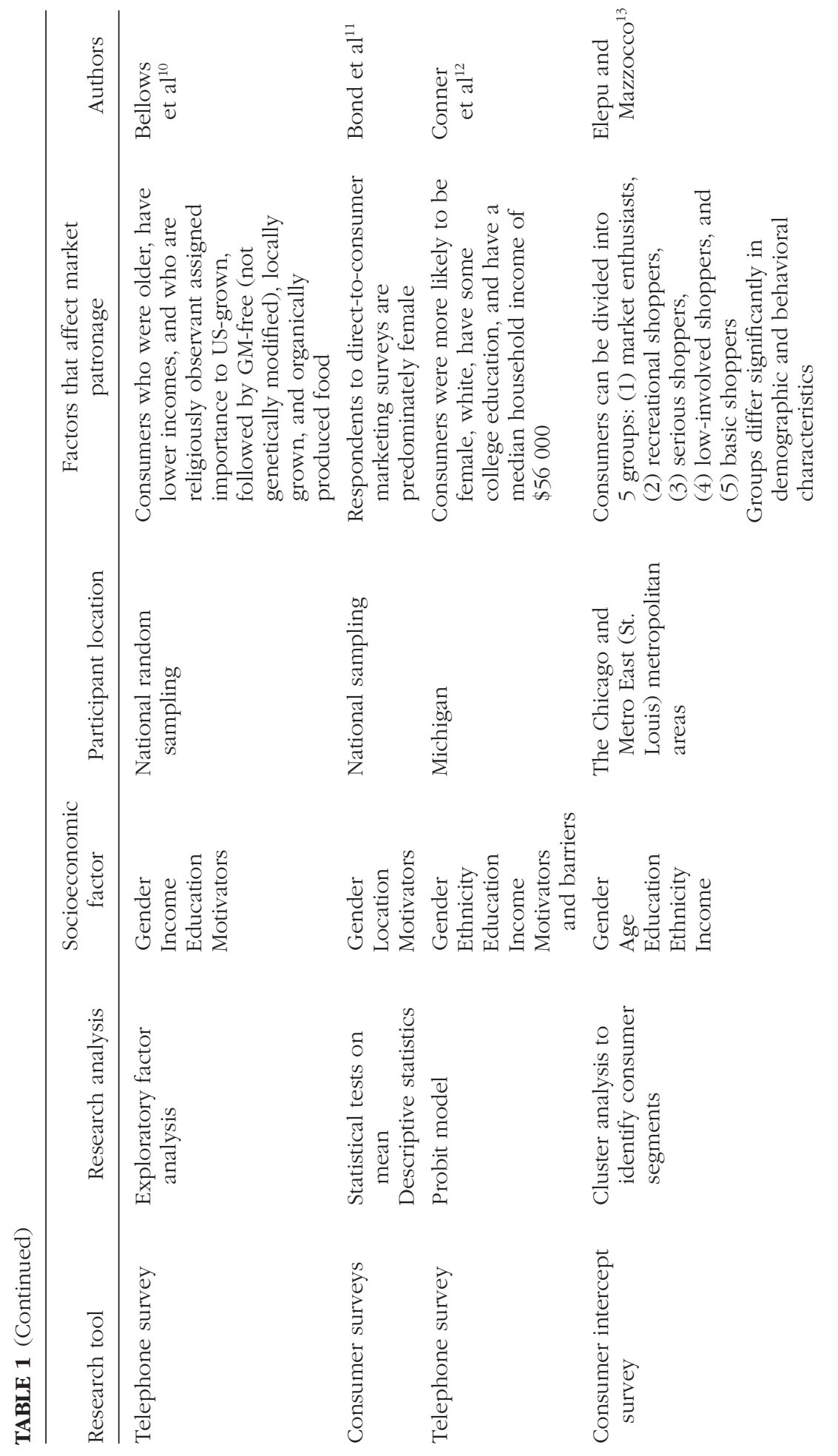




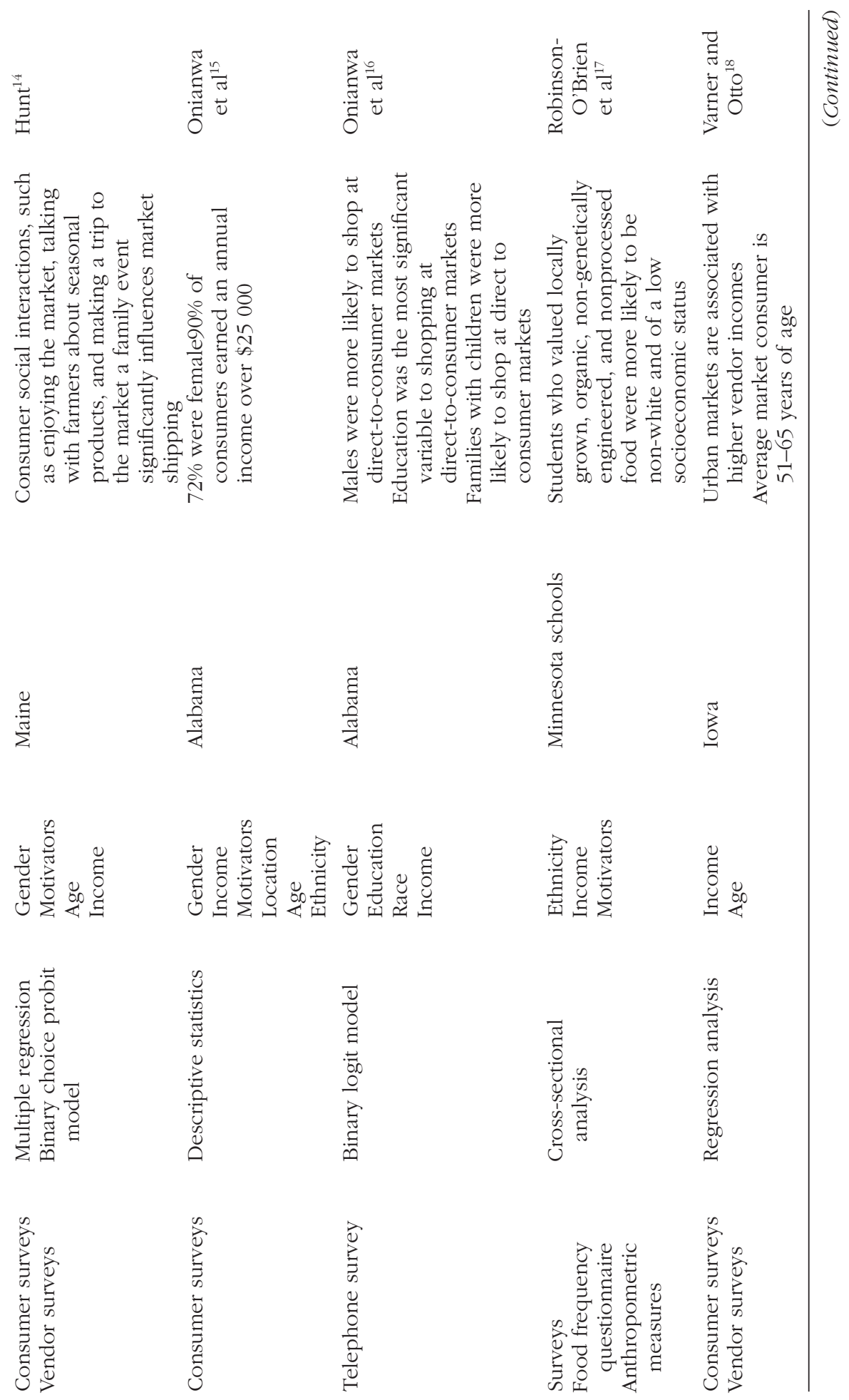




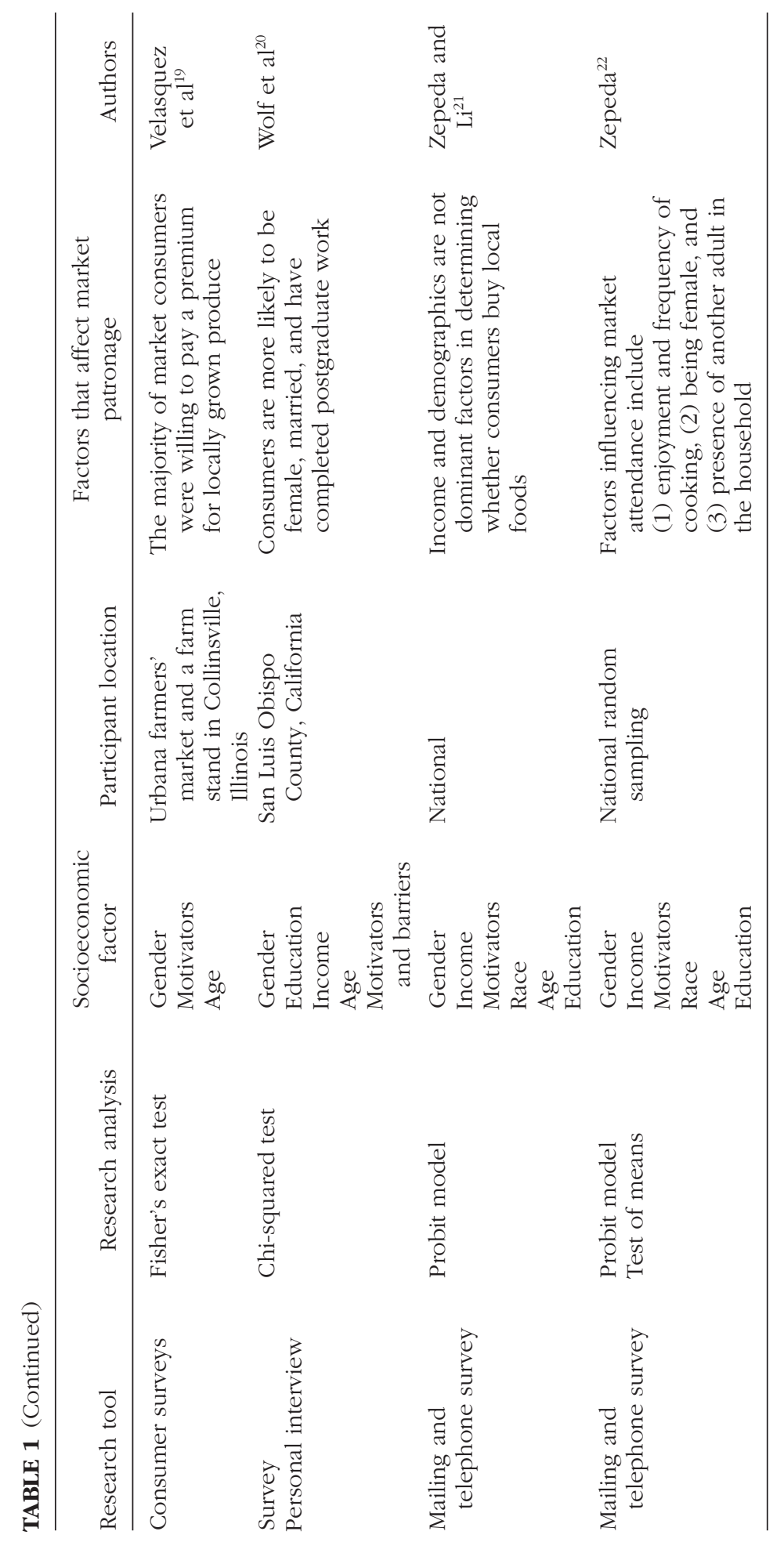


toward local foods. To gather information about primary household food shoppers' produce purchasing patterns, Bond and colleagues administered a national online survey. ${ }^{11}$ Questionnaire respondents were predominantly female, suggesting that they were responsible for produce shopping and/or that they may be more apt to complete surveys. It is important to keep in mind that though studies report that females are more likely to shop at farmers' markets, this does not necessarily mean that males are shopping at other food outlets instead. In fact, research suggests that the majority of males likely refer primary food shopping responsibilities to women. ${ }^{23,24}$

\section{Age}

A majority of studies included in this review concluded that the average farmers' market shopper was over 40 years of age., ${ }^{9,13,15,18,20}$ However, Velasquez et al's study of a farmers' market and farm stand in Illinois did diverge slightly. His research found an average customer age of 34 years. ${ }^{19}$ Because most studies suggest an average patron age over 40, Hunt's review of the social influences of customers on farmers' market vendors may shed some light on this specific demographic characteristic. ${ }^{14}$ According to Hunt, increased age was significantly related to more frequent social interactions. Following suit, it is possible that older community members patronize farmers' markets for social reasons in addition to food purchases. Bellows and colleagues' study adds information that both male and female consumers over 42 years of age were more likely to support natural food attributes such as those found at the farmers' market. ${ }^{10}$ Despite some consistency in average age characteristics, there is still not a critical mass of research evidence reporting age characteristics of farmers' market patrons. Future studies should explore and comment on the age differential of farmers' market shoppers, possibly relating age to income or other demographic factors.

\section{Personal Income}

Several studies found that farmers' market customers earned an average household income of $\$ 50000$ per year., ${ }^{92-14}$ Another study reported that 90\% of farmers' market customers earn more than $\$ 25000$ per year but did not differentiate between income levels above that number. ${ }^{15}$ Furthermore, Varner and Otto's study found positive association between per capita income in geographic areas in Iowa and farmers' market sales. ${ }^{18}$ Zepeda's study reported that, when compared to nonshoppers (ie, consumers who shop at other food outlet locations such as the supermarket or grocery store), farmers' market shoppers were more likely to earn between $\$ 15000$ and $\$ 30000$, lower than expected. ${ }^{22}$ The authors suggested that willingness to pay for farmers' market food may be a better predictor, regardless of income. 
Adding a longer-term perspective, Wolf and colleagues found that there was a wider distribution in middle and higher income levels in their 2005 study than in a similar study they conducted 10 years prior. ${ }^{20}$ This shift in results suggests that the consumer base at farmers' markets may be diversifying, possibly accounting for some of the conflicting data with regard to the incomes of farmers' market patrons.

It is also important to point out the role of nonmonetary (or nonincome) variables. Another investigation by Zepeda and $\mathrm{Li}$ found that income level did not affect local food purchases. ${ }^{21}$ The authors explained that the lack of correlation may be due to the fact that local food purchases were a minimal percentage of total income and total food purchases. Clearly, there is no consistent conclusion about the income of farmers' market shoppers.

\section{Educational Attainment}

Onianwa et al's analysis indicated that education is the greatest predictor of direct-market shoppers (ie, consumers who purchase food directly from the producer). ${ }^{16}$ In a study of 2 San Francisco farmers' markets, Alkon found that both markets attracted highly educated individuals, regardless of race or income. $^{7}$ Several other on-site surveys confirmed these findings, with $60 \%$ to $94 \%$ of respondents attaining at least some level of college education. ${ }^{13-15,20}$ For example, Conner and colleagues' Michigan telephone survey reported that farmers' market supporters had a mean education level of at least some college education. ${ }^{12}$

Conversely, Varner and Otto's study from Iowa claimed no significant differences in sales at farmers' markets where educational attainment was lower than the surrounding US Census area. ${ }^{18}$ That said, there are some inherent limitations to their research methodology. Rather than using primary data collection methodologies, Varner and Otto relied upon a combination of secondary data-census and location data-to make causal inferences about farmers' market shopper income. Similar to Varner and Otto's ${ }^{18}$ study, Zepeda and Li's investigations of farmers' market shoppers and local food consumers via a nationwide telephone and mail survey found no difference in education levels of farmers' market shoppers and nonshoppers or supporters of local food. ${ }^{21,22}$ Given the contradictory results in on-site versus off-site research, further research is needed to better understand divergent findings about the education of farmers' market shoppers.

\section{Race and Ethnicity}

Data from 9 studies included in this portion of the review present various findings with regard to race and ethnicity. Three studies found that a majority of shoppers were white. ${ }^{12,13,15}$ Although Onianwa et al found that 
white individuals were 1.8 times more likely to shop at a farmers' market, these results were not statistically significant. ${ }^{16}$ Other research showed that race is not an indicator of an individual's support (or lack thereof) for local food or farmers' markets. ${ }^{21,22}$ Additionally, research by RobinsonO'Brien et al reported on adolescent attitudes toward locally grown, organic, non-genetically engineered, and nonprocessed foods. ${ }^{17}$ Non-white respondents valued alternative production methods more than white respondents. Considering that $70 \%$ of respondents were Hmong American, the authors suggest that these unexpected results were due to racial differences regarding the valuation of alternative food production methods. Somewhat similarly, Alkon's studies of 2 demographically and geographically diverse farmers' markets from 2 different neighborhoods found that a majority of patrons at one market were white, whereas the majority at the other market were black. ${ }^{7,8}$ Conner and colleagues reported that the Latino population in their Michigan telephone survey valued farmers' markets but did not feel welcome because of cultural barriers. ${ }^{12}$ These data suggest that patronage of farmers' markets is related to location of individual markets as well as relative distance and cultural acceptability of farmers' markets in different racial or ethnic groups.

\section{Location}

Few studies reported the location of the farmers' markets in relation to consumers' residences. Of the 4 studies that did, shoppers reported a range of 6 to 17 miles. ${ }^{14,15,18}$ Baker et al reported that customers traveled 17 to $18 \mathrm{~min}$ to reach the market. ${ }^{9}$ More information about the location of farmers' markets may help community and market planners to decide the best avenues to increase food access, particularly among more remote individuals.

\section{Motivations for Shopping at Farmers' Market}

Fourteen studies from the consumer section of this literature review listed a variety of motivational factors. Some of the more common reasons cited for shopping at the farmers' market included fresh food, ,,14,15,19,20,25 highquality food, ${ }^{11-13,18,20}$ supporting local agriculture, $, 12,14,15,19,25,26$ and social appeal. ${ }^{9,13,19,26}$ Other motives reported include food safety, ${ }^{12}$ taste, ${ }^{20,26}$ and organic chemical- and pesticide-free foods. ${ }^{19,26}$ Despite its assumed importance, convenience was important to some shoppers, ${ }^{9}$ whereas for others it was not a determining factor. ${ }^{11,15}$ Similarly, price was a concern for some consumers ${ }^{11,15,20}$ and not for others. ${ }^{12,19,21,22}$ Given these findings, it is plausible that convenience and cost may be dependent on features relative to each farmers' market. That said, it is important to point out that these 2 motivators are consistent with the larger body of research about food purchases 
(ie, cost and convenience are important factors when deciding what foods to buy). ${ }^{27}$

Particular lifestyle traits also motivated consumers to shop at farmers' markets. In general, the enjoyment of cooking is associated with support for local food and farmers' markets. ${ }^{10,20,22}$ Other lifestyle factors associated with market shopping include religious observance, ${ }^{10,22}$ gardening, ${ }^{21,22}$ and an interest in health foods. ${ }^{10,21}$ Given the prominence of these diverse findings, it is conceivable that motivational factors are in fact better predictors of farmers' market patronage than demographics. ${ }^{21,22}$ Therefore, the degree to which lifestyle factors influence market shopping habits should be further explored.

With a slightly different approach to motivational research, Alkon investigated the ethical difference in motivations attributed to 2 San Francisco farmers' markets. ${ }^{7}$ Rather than examining individual motivations, Alkon looked at the ways in which markets sought to engage and attract patrons from an ethical foundation. The high-income market largely focused on environmental sustainability (eg, to connect with nature) but did not provide equal support to social justice issues, because affordability was not a concern. The low-income market primarily supported social justice topics (eg, race and inequality) and had only a slight focus on environmental sustainability but did not have enough clientele to support the economic livelihood of vendors.

It is clear that consumers are motivated by personal preferences for promotion or prevention of an outcome (eg, health or environmental concerns), food preferences, and socioecological constructs. Complex and multifaceted, the particulars of choice are not clearly understood and involve the interaction of many socioecological influences.

\section{Barriers}

Barriers to farmers' market shopping are often mentioned when addressing efforts to diversify the consumer base. Jilcott et al found that inconvenient location and hours were the biggest limitations to farmers' market shopping. ${ }^{28}$ In another investigation, location and price were reported as barriers to farmers' market attendance. ${ }^{29}$ As mentioned previously, Conner and colleagues' survey concluded that in order to attract the Latino consumers to farmers' markets in Michigan, cultural barriers (eg, language) would need to be bridged. ${ }^{12}$ Another publication referring to the same Michigan telephone survey study indicated that limited market hours, location, payment method uncertainty, and an unwelcoming atmosphere were all barriers to shopping at the market. ${ }^{25}$ Webber and colleagues partially explained some of these findings through an examination of food and retail qualities that are important to low-income households. ${ }^{30}$ Convenience with regard to all aspects of attaining food was primarily emphasized, even if that 
meant paying a higher price for items. Stressing the desire for convenience, one respondent suggested that the ideal shopping experience would be to place a farmers' market or produce stand inside the grocery store. ${ }^{30}$

\section{SUMMARY}

Given the preceding information about consumer research, it is clear that there is an assortment of complex and interrelated factors that influence an individual's choice to shop (or not to shop) at farmers' markets. There is convincing evidence that categorizes the typical farmers' market shopper as a middle-aged female who lives within proximal distance of the market. Furthermore, motivations and barriers span multiple levels of the socioecological model, demonstrating the multivariate complexity of choice. Still, many of the specifics regarding farmers' market patronage remain unclear. The degree to which individual traits and relational, organizational, community, social, and cultural factors influence choice remains unknown. Understanding the significance of these variables to individual decision-making processes will enable researchers to better answer a series of socioecological inquiries. For example, though research indicates that the majority of farmers' market shoppers are female, we do not know whether more females shop at the farmers' market because of their gender (an individual construct) or because of the social norm (a social construct) that positions women as primary food shoppers. Similarly, there is inconclusive evidence about the effects that personal income, educational attainment, and race/ethnicity have on farmers' market shopping patterns.

Although initially inconclusive, this information may actually indicate that the farmers' market consumer base is slowly diversifying. Demographics of farmers' market shoppers are perhaps beginning to better reflect the communities in which farmers' markets are situated. This is already evident in the study by Alkon in which characteristics of shoppers vary between the affluent area of North Berkley and the poorer community of West Oakland. ${ }^{7}$ Additionally, these findings may also suggest that individual constructs alone are not good proxies for determining behavior, ultimately indicating that a combination of socioecological characteristics influences farmers' market shoppers. It is not easy to pinpoint the precise makeup of the typical farmers' market shopper due to contextual differences unique to each community. Each food environment is situated within a particular socioecological context where, at the center, the individual's choice determines what he or she eats. That said, there are several concentric factors (ie, individual, social, community, and political) that influence such decisions. Further research should investigate the confluence of individual, social, community, and political contexts in which food choices are made in order to better define the matrix of socioecological constructs that impact choice. 
In particular, it would be useful if researchers developed a generalizable survey for farmers' markets to complete in order to ensure consistent information is obtained across sites. Table 1 reviews the lack of consistency in research tools and analytical methods utilized in research to date. As the number of farmers' markets continues to grow in the United States it may be beneficial for this survey to be available at a central location, such as the USDA Agriculture Marketing Service Website (http://www.ams.usda.gov/AMsv1.0) or Know Your Farmer, Know Your Food Website (http://www.usda.gov/wps/ portal/usda/knowyourfarmer?navid=KNOWYOURFARMER). Market managers could use survey results to tailor and diversify their market according to the consumer base in their area. It is possible that farmers' markets have completed surveys of their customers for their own benefit and have not shared them with the wider research community. This could be an untapped resource for understanding farmers' market shoppers. Compiling a database of the information collected from a consistent survey would be of use to researchers trying to understand the impacts that community food systems have on diet, community, economies, or the environment and their relationship to demographics.

In its broadest sense, this article seeks to better understand the who, what, where, when, why, and how much of the current farmers' market consumer base. Doing so provides a framework for practitioners, researchers, and communities to better understand how farmers' markets promote the goals of community food systems. Identifying the sociodemographic characteristics of the current farmers' market consumer base enables researchers to establish connections between the goals and outcomes of a community food system and how the diet, surrounding community, economy, and environment of patrons is impacted. Such collaboration will not only enrich the research base but also facilitate the development of foodscapes that better address the wants and needs of community-based consumers.

\section{REFERENCES}

1. Wilkins J, Eames-Sheavly M. A primer on community food systems: linking food, nutrition and agriculture. Available at: http://www.hort.cornell.edu/foodsys/ pdfs/Primer.pdf. Accessed October 4, 2011.

2. Martinez S, Hand M, Da Pra M, et al. Local food systems: concepts, impacts, and issues. Available at: http://www.ers.usda.gov/Publications/ERR97/ERR97. pdf. Accessed October 4, 2011.

3. Bourlakis MA, Weightman PWH. Food Supply Chain Management. Wiley Online Library; 2004. Available at: http://onlinelibrary.wiley.com/doi/10.1002/ 9780470995556.fmatter/summary. Accessed November 1, 2011. 
4. Agricultural Marketing Service. Farmers market growth: 1994-2010. Available at: http://www.ams.usda.gov/AMSv1.0/. Accessed September 3, 2011.

5. McWilliams J. Is locavorism for rich people only? Available at: http://www. freakonomics.com/2009/10/14/is-locavorism-for-rich-people-only/. Accessed October 4, 2011.

6. Stokols D. Translating social ecological theory into guidelines for community health promotion. Am J Health Promot. 1996;10:282-298.

7. Alkon A. From value to values: sustainable consumption at farmers markets. Agric Human Values. 2008;25:487-498.

8. Alkon AH. Paradise or pavement: the social constructions of the environment in two urban farmers' markets and their implications for environmental justice and sustainability. Local Environ. 2008;13:271-289.

9. Baker D, Hamshaw K, Kolodinsky J. Who shops at the market? Using consumer surveys to grow farmers' markets: findings from a regional market in northwestern Vermont. J Extens. 2009;47(6):1-9.

10. Bellows AC, Alcaraz VG, Hallman WK. Gender and food, a study of attitudes in the USA towards organic, local, US grown, and GM-free foods. Appetite. 2010;55:540-550.

11. Bond JK, Thilmany D, Bond CA, Govindasamy R, Thornsbury S. Direct marketing of fresh produce: understanding consumer purchasing decisions. Choices. 2006;21:229-236.

12. Conner D, Colasanti K, Ross R, Smalley S. Locally grown foods and farmers markets: consumer attitudes and behaviors. Sustainability. 2010;2:742-756.

13. Elepua G, Mazzocco M, Goldsmith P. Consumer segments in urban and suburban farmers markets. Int Food Agribus Manag Rev. 2010;13(2):3-14.

14. Hunt A. Consumer interactions and influences on farmers' market vendors. Renew Agric Food Syst. 2007;22:54-66.

15. Onianwa O, Mojica M, Wheelock G. Consumer characteristics and views regarding farmers markets: an examination of on-site survey data of Alabama consumers. J Food Distrib Res. 2006;37:121-124.

16. Onianwa O, Wheelock G, Mojica M. An analysis of the determinants of farmerto-consumer direct-market shoppers. J Food Distrib Res. 2005;36:132-134.

17. Robinson-O'Brien R, Larson N, Neumark-Sztainer D, Hannan P, Story M. Characteristics and dietary patterns of adolescents who value eating locally grown, organic, nongenetically engineered, and nonprocessed food. J Nutr Educ Behav. 2009;41:11-18.

18. Varner T, Otto D. Factors affecting sales at farmers' markets: an Iowa study. Appl Econ Perspect Policy. 2008;30:178-187.

19. Velasquez C, Eastman C, Masiunas J. An assessment of Illinois farmers' market patrons' perceptions of locally-grown vegetables. J Veget Sci. 2005;11:17-26.

20. Wolf M, Spittler A, Ahern J. A profile of farmers' market consumers and the perceived advantages of produce sold at farmers' markets. J Food Distrib Res. 2005;36:192-201.

21. Zepeda L, Li J. Who buys local food? J Food Distrib Res. 2006;37(3):9-14.

22. Zepeda L. Which little piggy goes to market? Characteristics of US farmers' market shoppers. Int J Consum Stud. 2009;33:250-257. 
23. French SA, Wall M, Mitchell NR. Household income differences in food sources and food items purchased. Int J Behav Nutr Phys Act. 2010;7:3-7.

24. French SA, Wall M, Mitchell NR, Shimotsu ST, Welsh E. Annotated receipts capture household food purchases from a broad range of sources. Int J Behav Nutr Phys Act. 2009;6:6.

25. Colasanti K, Conner D, Smalley S. Understanding barriers to farmers' market patronage in Michigan: perspectives from marginalized populations. J Hunger Environ Nutr. 2010;5:316-338.

26. Conner DS, Montri AD, Montri DN, Hamm MW. Consumer demand for local produce at extended season farmers' markets: guiding farmer marketing strategies. Renew Agric Food Syst. 2009;24:251-259.

27. Glanz K, Basil M, Maibach E, Goldberg J, Snyder D. Why Americans eat what they do: taste, nutrition, cost, convenience, and weight control concerns as influences on food consumption. J Am Diet Assoc. 1998;98:1118-1126.

28. Jilcott SB, Hurwitz J, Moore JB, Blake C. Qualitative perspectives on the use of traditional and nontraditional food venues among middle-and low-income women in Eastern North Carolina. Ecol Food Nutr. 2010;49:373-389.

29. Webber C, Dollahite J. Attitudes and behaviors of low-income food heads of households toward sustainable food systems concepts. J Hunger Environ Nutr. 2008;3:186-205.

30. Webber C, Sobal J, Dollahite J. Shopping for fruits and vegetables. Food and retail qualities of importance to low-income households at the grocery store. Appetite. 2010;54:297-303. 